\title{
The Effect of Logotherapy Oriented Group Counseling on Post-Traumatic Embitterment Disorder*
}

\section{Betül DÜŞÜNCELI ${ }^{* *}$}

\section{Mustafa KOÇ***}

\begin{abstract}
The basic aim of this study is to examine effect of logotherapy oriented group counseling application on post-traumatic embitterment disorder. The study was carried out by experimental design because it is aimed to determine causeeffect relationship between independent variable (Logotherapy oriented group counseling) and dependent variable (Post-Traumatic Embitterment Disorder). The design of the study is the pretest-posttest control group design from true experimental designs. Participants are 22 university students whose posttraumatic embitterment disorder symptoms levels were high. It is randomly assigned that which participant will be in the experimental or control group. Each group was formed from 11 university students. Data had been collected by PostTraumatic Embitterment Disorder Scale. While experimental group was applied Logotherapy oriented group counseling for ten weeks, any treatment program applied to control group. The same scale was applied three times for preexperimental, post-experimental, and follow up processes. Data were analyzed by SPSS package program. According to findings of the research, Logotherapy oriented group counseling has effect on reducing the post-traumatic embitterment disorder symptoms. Findings were discussed by associating with the related literature and suggestions were made in consideration of findings.
\end{abstract}

Keywords: Logotherapy, Post-Traumatic Embitterment Disorder, Group Counseling.

\footnotetext{
${ }^{*}$ This study was produced from the doctoral thesis prepared by the first author under the supervision of the second author.

** Orcid ID: https://orcid.org/0000-0002-6794-8811, Assist. Prof. Dr., Sakarya University, Faculty of Education, Educational Sciences - Guidance and Psychological Counseling, bbayraktar@sakarya.edu.tr *** Orcid ID: https://orcid.org/0000-0002-8644-4109, Prof. Dr., Düzce University, Faculty of Education, Educational Sciences - Guidance and Psychological Counseling, mustafa.koc@duzce.du.tr
} 


\section{INTRODUCTION}

Individuals experience many incidents in their daily lives that they do not want to face with. In some cases, trauma causes the individual to face the most extreme points of despair and fear (Gölge, 2005). Traumatic experiences make the world a place more difficult to predict what will happen and a more terrifying place for them (Murray, 2001). There are similar events in history. It was observed that individuals who have suffered the negative consequences of the fall of the Berlin Wall in Germany showed the diagnostic criteria of post-traumatic stress disorder and adjustment disorder, however these individuals resorted to treatment with different complaints that do not fully correspond to these two disorders (Linden, 2003). It was observed that the problems experienced by these individuals did not correspond to a disorder in the diagnostic criteria of DSM-IV because the problems they experienced were due to disappointment or humiliation (Linden, Baumann, Lieberei, \& Rotter, 2007). This disorder is called "Post Traumatic Embitterment Disorder" (PTED) due to the fact that the precursor psychopathological properties include a feeling of constant embitterment (Linden, 2003). It can be said that individuals with this disorder see the event as "unfair" and react with resentment and emotional arousal when the event is discussed (Linden et al., 2007).

Negative life events and traumatic experiences manifest themselves in individuals with embitterment as one of the common universal reactions, with differences depending on cultural differences (Ünal, Güney, Kartalcı and Reyhani, 2011). According to Linden et al. (2007), the main criterion in PTED is the development of clinically significant emotional and behavioral symptoms following a normal negative life event which was perceived as an unusual event by the individual. The individual blames the negative life event as the cause of their discomfort. The incident is seen as unjust, insulting and humiliating. The reaction of the individual who experienced the incident involves embitterment, despair, anger and helplessness and the individual acts with affective arousal when recalling the incident. The characteristic symptoms seen after the incident include repetitive compulsive thoughts and a persistent negative change in their mental health. Their normal emotional state can be observed when the individual can focus their attention. The trigger event is an event that anyone can experience (Linden et al., 2007).

While people experience negative life events in life, how each person can cope with these events can change. In this sense, it is the theorist Frankl who provides an important perspective with Logotherapy. Frankl (1973), the founder of logotherapy, stated that the will to meaning is a universal human need for survival. When life becomes full of pain, what makes it possible to stand and hope again is the will to meaning. Frankl considers the will to meaning as the basic desire of mankind (McAdams, 2012) and a distinctive feature of being human (Altıntaş, \& Gültekin, 2005). The meaning of life is a complex and fundamental structure that is very important for human development (Weinstein, Ryan \& Deci, 2012). In life, the meaning of life can change at any time, but it is never lost. According to Frankl, the individual can find the meaning of life in three different ways: (1) Creating a work or doing a job (creative values), (2) Experiencing something or 
interacting with a person (experiential values), (3) Developing an attitude towards inevitable pain (attitudinal values) (Frankl, 2007; Frankl, 1967a).

Existential frustration, which is one of the important concepts of logotherapy, means the prevention of the demand for meaning (Frankl, 2007). It is a human experience that everyone can live since the meaning of life can be obscured by external and internal factors (Wong, 2002). Over time, this feeling leads to existential vacuum (Budak, 2003). It cannot be argued that existential vacuum solely disrupts mental health, however the existential vacuum causes more of a spiritual depression (Frankl, 1967b; Rice, 2004).

If a person's will to meaning is accomplished, that person becomes happy and can also endure pain (Frankl, 2005). Linden claim that when people encounter trauma, they find themselves in an existential process and question the meaning in their lives. They ask for existential questions such as "Why me?" and feel that they have lost control (Linden et al., 2007). Magwaza (1999), in their study on South Africans, have reported that the individuals lost the meaning of life as a dominant feeling after trauma due to racism experinced and approximately $77 \%$ of these individuals stated that they felt emotionless and helpless. Individuals who face a vital threat directly affecting them need to look for a meaningful event in the process of reintegration (Taylor, 1983).

The search for meaning involves the necessity of understanding the reason of an event and its effect. When a person understands the cause of an event, that person can understand the meaning of the event and what it symbolizes in their own life (Taylor, 1983). To think that they are individuals who fight injustice for justice instead of traumatic thoughts will help them to determine a positive attitude even if they cannot change the event and its results (Magwaza, 1999). In this manner, based on the assumption that people living with PTED regard the life not worth living, and that the feeling of losing the meaning of life is seen in these individuals, it is thought that logotherapy will help the individuals with PTED to fill the gap related to the search for the meaning of life. It has been planned to be an effective approach to encourage the individuals who live with PTED to change the changeable situations and to determine a healthy attitude towards irreversible situations by raising awareness about the changeable and irreversible situations in logotherapy. In the present study, the efficacy of logotherapy oriented psychological group counseling was investigated on individuals with PTED. In this context, the main hypothesis of the research was as follows;

H0: Logotherapy-oriented group counseling is not effective in reducing PTED.

H1: Logotherapy-oriented group counseling is effective in reducing PTED.

This study is original due to the fact that it proposes a different perspective in reducing PTED symptoms by logotherapy, up-to-date since PTED was first proposed by Linden (2003) and is still at the definition stage and is functional in terms of guiding the mental health workers studying on similar cases in this field. 


\section{METHOD}

The research was carried out with experimental method. Experimental research involves manipulating the independent variable by the researcher and comparing the obtained measurements of the dependent variable of the subjects in at least two conditions (Büyüköztürk, Çakmak, Akgün, Karadeniz \& Demirel, 2008).

Pretest-Posttest Control Group Design, which is one of the real experimental designs, was used in the study. In this pattern which is one of the commonly used patterns in education and psychology fields; first, two groups are formed by random assignment from the previously determined subject pool. One of the groups is determined randomly as the experiment and the other the control group. Then, measures related to dependent variable are taken from the subjects in the two groups before application. In the application process; The experimental process whose effect is tested is applied to the experimental group and not to the control group. In the last stage; The measurements of the dependent variable of the subjects in the groups are obtained using the same tool or a similar form. In the application process; The experimental process whose effect is tested is applied to the experimental group and not to the control group. In the last stage; The measurements of the dependent variable of the subjects in the groups are obtained using the same tool or a similar form. At the same time, this pattern has two main advantages. First, the measurements obtained under the same conditions will be highly correlated in many experiments. It is decreases the margin of error while increasing statistical power. Another is to save time and effort because the same subjects are tested in each procedure (Büyüköztürk et al., 2008). The pattern of the research is given below.

\section{Tablo 1.}

The Pattern of the Research

\begin{tabular}{lllll}
\hline Groups & Pre-test & Process & Post-test & Follow-up test \\
\hline \multirow{4}{*}{ Experiment } & Post Traumatic & Logotherapy & Post Traumatic & Post Traumatic \\
& Embitterment & Oriented & Embitterment & Embitterment \\
& Disorder Scale & Group & Disorder Scale & Disorder Scale \\
& & Counseling & & \\
\cline { 2 - 5 } Control & Post Traumatic & No Process & Post Traumatic & Post Traumatic \\
& Embitterment & & Embitterment & Embitterment \\
& Disorder Scale & & Disorder Scale & Disorder Scale
\end{tabular}

In the study, the use of logotherapy-oriented group counseling was an independent variable and PTED was a dependent variable. 


\section{Study Group}

In the first stage of the study, PTED scale was applied to 352 (61.8\%) females and 218 (38.2\%) males, a total of 570 students out of 3900 students studying at Sakarya University Faculty of Education in Turkey by stratified random sampling method. In the second stage of the study, a total of 84 subjects, 56 (66.6\%) females and 28 (34.4\%) males, were determined to get high scores from the PTED scale. Face-to-face and telephone interviews were carried out with 84 people that comprise the experimental and control groups. As a result of the interviews, the experimental and control groups were formed consisting of 22 individuals, who were regarded to be suitable for the counseling process by the researcher, agreed to participate in the group counseling process and randomly selected with unbiased group assignment. A total of 22 participants (11 of which were in the control group and 11 in the experimental group) who had experienced a negative life event were included in the study.

\section{Data collection tools}

\section{Post Traumatic Embitterment Disorder Scale (PTED Scale)}

It is a 19-item, 5-point Likert type, self-reported scale. The scores of the scale vary between 0 and 76. The higher the score means, the higher the severity of the pathology. The scale was developed by Linden, Rotter, Baumann, \& Lieberei (2009) based on the symptoms of patients admitted to the clinic to examine the severity and the characteristics of embitterment developed as a result of negative events. The reliability/validity study of the Turkish version of the scale was carried out by Ünal et al. (2011).

In the Turkish adaptation of the scale, Ünal et al. (2011) reached 1333 people from four different groups. These groups; 1. Inpatients and outpatients who were diagnosed as Post Traumatic Stress Disorder; 2. Inpatients receiving at least one of the diagnoses of general psychiatric illness; 3 . Persons who have been traumatized in the normal population without any psychiatric diagnosis; 4. Persons without a psychiatric diagnosis in the normal population. The Post Traumatic Embitterment Disorder Scale (PTED-Self-Rating Scale) was translated into Turkish by two psychiatrists, a clinical psychologist and a linguist. After the translation from Turkish to English, the original and Turkish forms of the scale were administered to 15 faculty members of Medicine faculties who were familiar with English and Turkish with a week interval to test item equivalence. The correlation between these two applications was found to be $r=0.95$. Cronbach alpha coefficient was calculated for the validity and reliability analyzes of the scale, test-retest method, split-half method, principal component analysis with Warimax rotation and criterion related validity analyzes were made. Factor analysis indicated a two-factor structure. These two factors explained $54.47 \%$ of the total variance. Factor loads of the items were found to be 0.37 and above. This study shows that; Embitterment Post Traumatic Disorder Scale (PTED Scale) as a valid and reliable scale is available outside the clinical setting in Turkey (Ünal et al, 2011). 


\section{Semi-Structured Interview Form for Post-Traumatic Embitterment Disorder}

The semi-structured interview form for PTED consisted of 23 items and was created by Linden et al. (2007). The interview form was translated into Turkish by the researcher.

\section{Data Collection}

In the first stage, the individuals who scored higher in the PTED scale were determined, and in the second stage, the pretest, posttest control group design was used. In the experimental design study. Logotherapy-oriented group was carried out in 10 sessions with the experimental group. No procedure was carried out with the control group during this period.

\section{Data Analysis}

SPSS software was used for the statistical analysis data. Skewness and kurtosis values were calculated to determine whether there was a normal distribution. Shapiro-Wilk normality test (Can, 2013) was adopted since the number of subjects in the study group was less than 30 . The homogeneity of the variances was checked by the Levene test. Mauchly's Test of Sphericity was used for the assumption of sphericity.

It was found that the skewness value of the scores obtained from the pretest measurement of the individuals in the experimental group was skewed to the right at the level of .47, and the kurtosis value was slightly skewed to the left by -1.25 . In the control group, it was found that the skewness value of the scores obtained from the pretest measurement of PTED scale was skewed to the right at the level of .45, and the kurtosis value was -, 66 very slightly skewed to the left. The cases where the $\mathrm{z}$-statistic to be obtained by dividing the skewness coefficient by the standard error is between -1.96 and +1.96 are considered as normal distribution (Büyüköztürk, 2012; Can, 2013).

In the Shapiro-Wilk normality test, it was seen that there was no statistically significant difference between the distribution observed in PTED measurements and the predicted distribution for the experimental and control groups ( $p>.05)$. In the homogeneity test of variances; When the values obtained from the pretest from the PTED scale of the experimental and control groups were examined, it was seen that there was no difference between the variances of the groups (PTED F = 1.56, p> .05). When the values obtained from the posttest were examined, it was seen that there was no difference between the variances of the groups (PTED F = 1.77; $\mathrm{p}>$.05) and the values obtained from the followup test, no difference was observed between the variances of the groups (PTED F = 1.56; $p>$.05).According to the Mauchly Sphericity Test results, it is seen that the sphericity assumption is provided for repeated measurements taken at different times from the PTED scale (W (2) = .773, p> .05 for PTED). For this reason, the F-ratio, calculated automatically by SPSS, was used by Greenhouse-Geisser Correction while examining the intra-group effect regarding the measurements taken from the PTED scale. As a result of the calculations, parametric tests were used to analyze the data. 


\section{FINDINGS}

In this section, statistical analyses conducted to test the hypotheses proposed in accordance with the aim of the research and the findings obtained from these analyses are given. The main aim of the study was to examine the effects of the 10 -week logotherapy-oriented group counseling program prepared by the researcher on PTED. In accordance with the main hypothesis of the study, the significance of the difference in the changes in the repeated measures of PTED-dependent variable between the experimental and control groups was tested with variance analysis for repetitive measurements on the single factor.

The main hypothesis of the study was described as 'logotherapy oriented psychological application is effective in reducing the PTED". Variance analysis was used for repeated measures on one factor to test this hypothesis. The mean and standard deviation values of the PTED pre-test, post-test and follow-up test scores of the individuals in the experimental and control groups were calculated before ANOVA and the obtained data are given in Table 2 .

Table 2 .

Mean and Standard Deviation Values for Post Traumatic Embitterment Disorder Pre-Test, Post-Test and Follow-up Test Scores of the Experimental and Control Groups

\begin{tabular}{clrrr}
\hline \multirow{2}{*}{ Groups } & PTED pre-test, post-test and follow-up test & \multirow{2}{*}{$N$} & $\bar{X}$ & df \\
& measurement results & & & \\
\hline \multirow{3}{*}{ Experiment } & Pre-test & 11 & 56.82 & 7.05 \\
& Post-test & 11 & 22.18 & 7.28 \\
& Follow-up Test & 11 & 20.45 & 7.35 \\
\cline { 2 - 6 } Control & Pre-test & 11 & 56.55 & 5.43 \\
& Post-test & 11 & 55.09 & 5.28 \\
& Follow-up Test & 11 & 54.91 & 9.71 \\
\hline
\end{tabular}

Examining the descriptive statistical analysis results for PTED scale pre-test, post-test and follow-up tests in the experimental and control groups, the mean score for the PTED scale pre-test in the experimental group was $(\bar{X}=56.82)$, the standard deviation for pre-test was $(\mathrm{df}=7.05)$, the mean post-test score was $(\bar{X}=22.18)$, the standard deviation for posttest was $(\mathrm{df}=7.28)$ and the mean follow-up test score was $(\bar{X}=20.45)$, and the standard deviation for the follow-up test was $(\mathrm{df}=7.35)$. Examining the descriptive statistical analysis results for PTED scale pre-test, post-test and follow-up tests in the control group, 
the mean score for the PTED scale pre-test in the control group was ( $\bar{X}=56.55)$, the standard deviation for pre-test was $(\mathrm{df}=5.43)$, the mean post-test score was $(\bar{X}=55.09)$, the standard deviation for post-test was $(\mathrm{df}=5.28)$ while the mean follow-up test score was ( $\bar{X}=54.91)$, and the standard deviation for the follow-up test was ( $\mathrm{df}=9.71)$.

Table 3.

Repeated Measures ANOVA Results for Post Traumatic Embitterment Disorder Pre-Test Post-Test and Follow-up Test Scores of the Experimental and Control Groups

\begin{tabular}{lcccccc}
\hline Source of Variance & Sum of square & df & $\begin{array}{c}\text { Mean of } \\
\text { square }\end{array}$ & F & $p$ & $\eta^{2}$ \\
\hline $\begin{array}{l}\text { Intergroups } \\
\begin{array}{l}\text { Intervention } \\
\text { (D/K) }\end{array}\end{array}$ & 9516.667 & 21 & & & & \\
Fault & 8252.182 & 1 & 8252.18 & 130.52 & .000 & .867 \\
Intragroups & 1264.485 & 20 & 63.224 & & & \\
Time & 11096 & 44 & & & & \\
(pre-test, post- & 5042.030 & 2 & 2521.015 & 55.405 & .000 & .735 \\
test, follow-up & & & & & & \\
test) & 4233.909 & 2 & 2116.95 & 46.52 & .000 & .699 \\
Intervention*Time & 1820.061 & 40 & 45.502 & & & \\
Fault & 14558.697 & 61 & & & & \\
Total & & & & & & \\
\hline
\end{tabular}

As given in Table 3, the effect of the variance analysis on the mean scores obtained from the PTED pre-test, post-test and follow-up test measurements of the individuals in the experimental and control groups was found to be significant and the effect size of the eta square value was found to be $\mathrm{F}_{(1-21)}=130.52 ; p<.001, \eta^{2}=.867$. In other words, there is a significant difference between the mean values of the scores obtained from PTED scale, regardless of the pre-test, post-test and follow-up test measurements in the experimental and control groups. It was found that there were differences between all of the measurements carried out at different times, the main effect of time was significant and the impact value of the eta square was calculated as $\left(\mathrm{F}_{(2-40)}=55.405 ; p<.001, \eta^{2}=.735\right)$. This result showed that, regardless of the group, the differences between the mean values of pre-test, post-test and follow-up tests were statistically significant. In addition, it was seen that the effects of intervention and time were also significant $\left(\mathrm{F}_{(2-40)}=46.52 ; p<.001\right)$. 
The calculated eta square value $\left(\eta^{2}=.699\right)$ showed that the logotherapy oriented group counseling was effective on PTED.

Accordingly, it was found that the PTED levels of the subjects in the experimental and control groups showed significant differences after the experiment, and that the common effects of repeated measures on the PTED in different groups were significant.

\section{Table 4.}

ANOVA Results of the Repetitive Measurements of Post Traumatic Embitterment Disorder according to Wilk's lambda test.

\begin{tabular}{llllll}
\hline Impact & Wilks $^{\prime} \lambda$ & $\mathrm{Df}$ & $\mathrm{F}$ & \multicolumn{1}{l}{$\eta^{2}$} \\
\hline Time & .136 & 2 & 60.338 & .000 & .864 \\
Time* Intervention & .157 & 2 & 50.943 & .000 & .843 \\
\hline
\end{tabular}

Examining the analysis of variance given in Table 4, a significant change was found for PTED time (Wilk's $\lambda=.136, \mathrm{~F}_{(2)}=60.338 ; p<.001$ ). Similarly, time*intervention interactions were found to be significant (Wilk's $\lambda=.157, \mathrm{~F}_{(2)}=50.943 ; p<.001$ ). According to these results, compared to the control group, it was found that the PTED levels of the individuals in the experimental group showed changes in the pre-test, post-test and follow-up measurements and this change was significant. 


\section{Table 5.}

The Mean and Standard Error values of Pre-test, Post-test and Follow-up Tests in the Experimental and Control Groups According to Post-Traumatic Embitterment Variable, Lower and Upper Limit values and Reliability Levels

Measurement: MEASUREMENT 1

\begin{tabular}{llllll}
\hline & & & & $\begin{array}{l}95 \% \\
\text { Interval }\end{array}$ & Confidence \\
\hline Groups & Factor 1 & Mean & Std. Error & $\begin{array}{l}\text { Lower } \\
\text { Limit }\end{array}$ & $\begin{array}{l}\text { Upper } \\
\text { Limit }\end{array}$ \\
\hline Experiment & Pre-test & 56.82 & 1.90 & 52.86 & 60.78 \\
& Post-test & 22.18 & 1.92 & 18.18 & 26.18 \\
& Follow-up Test & 20.45 & 2.60 & 15.04 & 25.87 \\
\hline Control & Pre-test & 56.55 & 1.90 & 52.59 & 60.50 \\
& Post-test & 55.09 & 1.92 & 51.09 & 59.09 \\
& Follow-up Test & 54.91 & 2.60 & 49.49 & 60.33 \\
\hline
\end{tabular}

The mean PTED scores, standard errors and confidence intervals of the experimental and control groups are given in Table 4. Examining Table 5, it was seen that the confidence intervals of PTED levels in the post-test and follow-up test of the experimental and control groups did not intersect. The PTED pre-test confidence interval of the experimental group was between 52.86 and 60.78. The PTED post-test confidence interval of the experimental group was between 18.18 and 26.18. The PTED follow-up test confidence interval of the experimental group was between 15.04 and 25.04. The PTED pre-test confidence interval of the control group was between 52.59 and 60.50. The PTED post-test confidence interval of the control group was between 51.09 and 59.09. The PTED follow-up test confidence interval of the control group was between 49.49 and 60.33. According to these results, the PTED post-test and follow-up test confidence intervals of the individuals in the experimental group were different from those of the control group. This result showed that the logotherapy oriented group counseling was effective on PTED.

To test the results of the analysis of the variance performed to test the main hypothesis of the research, and to examine the results of the analysis and to interpret the results of the research, the interaction graph of the ANOVA test is given in Figure 1. 


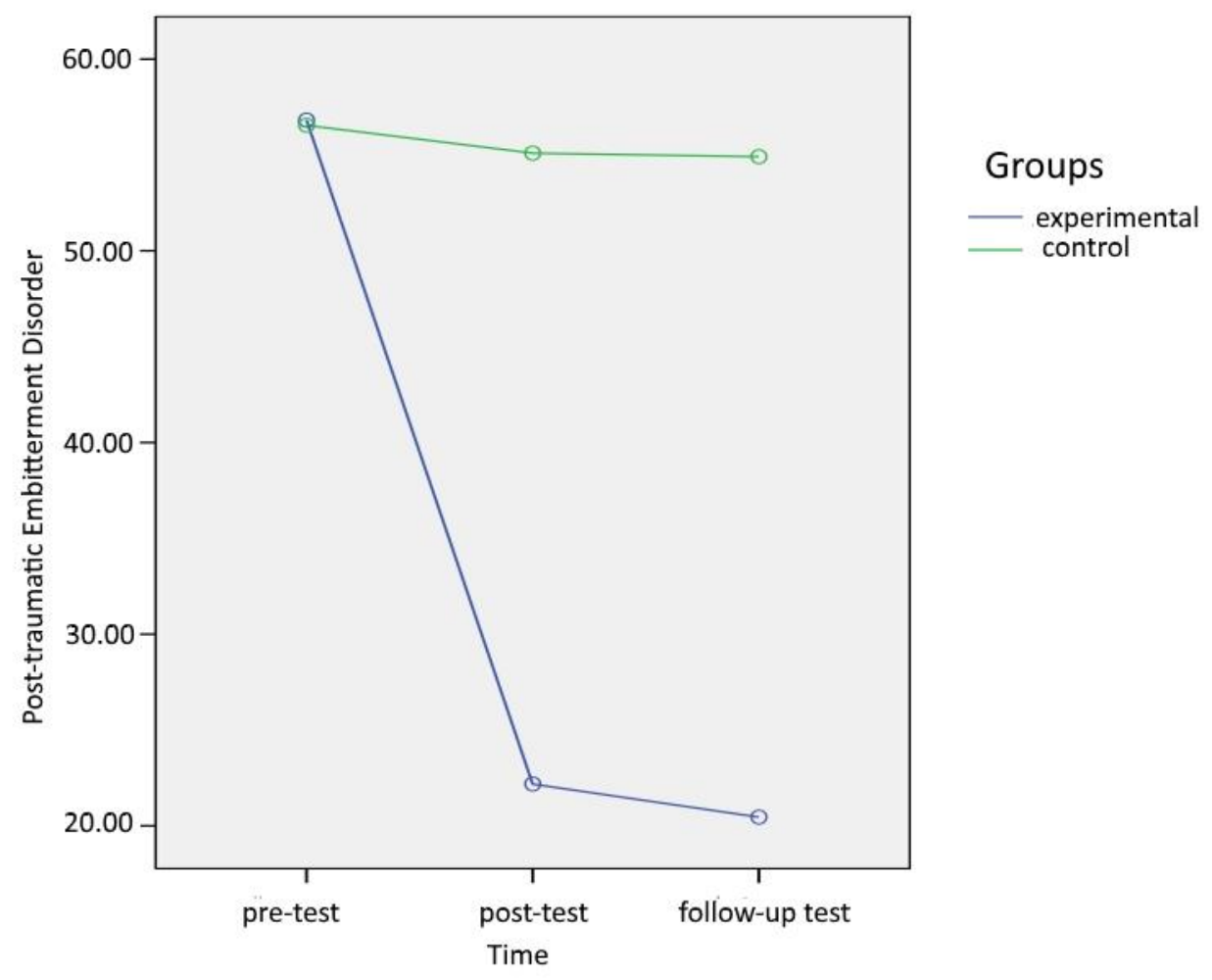

Figure 1. The graph for the mean values of pre-test, post-test and follow-up test measurements of Post-Traumatic Embitterment scores in the experimental and control groups.

Examining the interaction graph given in Figure 1, it was seen that there was a decrease in the PTED post-test scores for the individuals in both experimental and control groups. It was seen that this decrease was higher in the experimental group than that in the control group. This result showed that the experimental process (Logotherapy-oriented Group Psychological Counseling) was effective on PTED.

In addition, during the one-month period following the completion of the experimental procedure, it was observed that the decrease in the PTED scores continued for the experimental group, while the same situation was not observed for the control group. As a result, examining Figure 1, the graph supported the findings obtained in the research. Taking all the findings into consideration, it can be argued that Logotherapy-oriented Group Psychological Counseling is an effective therapy method for PTED. This result verifies the hypothesis "Logotherapy-oriented Group Psychological Counseling is effective in reducing PTED". 


\section{RESULTS, DISCUSSIONS AND SUGGESTIONS}

In the present study, it was seen that PTED levels of the individuals at the initial point (pre-test) in the experimental group, the resultant (post-test) and the follow-up results which tests the persistence of the effect were significantly different. Furthermore, considering that individuals in the control group passed the scale application and preinterview stages, it is possible that they perceived these stages as a support mechanism and have experienced a temporary relief. Indeed, this improvement did not cause a major change between the mean scores of the scale in the control group (pre-test and post-test values), however the significance between pre-test and post-test was not preserved during the follow-up period. This result showed that the experimental application (Logotherapy-oriented Group Psychological Counseling) was effective on PTED.

In the present study, psychological counseling process was planned and implemented to a logotherapy-oriented group for PTED which was presented as a new disorder category according to Linden et al. (2007). This study is the first on this subject since there were no previous studies found on this subject in the literature. In other studies, on PTED, it was seen that the participants were usually inpatients (Linden et al., 2007). In this context, this study presented data from a different sample group in terms of its application to university students. In addition, the study is important in terms of presenting PTED symptoms of individuals in Turkish society, life events that people perceive as traumatic, how they are affected by these events and a section of coping methods.

Individuals need to learn that fighting is good when they can win and have the control, however it is a very important and valuable human capacity to endure the inevitable (Linden et al., 2007). Acceptance of things that cannot be changed is one of the important sources proposed to deal with the existential coping and stress that includes the meaning of life and the purpose of the existence of the person (Wong, Wong, \& Scott, 2006). Thus, individuals, instead of complaining about the experiences of the clients, can try to search for a meaning in the events, and have a chance to gain something positive with a positive attitude, instead of losing something with a negative attitude.

Individuals with PTED consider the event they experience as traumatic. They remember the day and time of the onset of their painful life, and perceive themselves as frustrated, injured, hence, traumatized. (Hasanoğlu, 2008; Linden et al., 2007). The data obtained in this study supported this result and it was seen that the individuals described the event, environment and time they experienced in detail during group counseling. At the same time, the members of the group stated that they considered the negative life event to be unfair, that they felt hurt and desperate. In a study on post-traumatic cognitive changes carried out with South Africans, 91\% of the participants with similar qualifications described the event they experienced as unfair (Magwaza, 1999).

In the study, in the letter writing activity where the participants had the chance to express their feelings and thoughts to the person causing the negative life event, the group members expressed their regrets about the event, their anger to the individual who caused the event, and sometimes even their feelings of revenge. Some of the members of 
the group, albeit stating that the event they experienced was painful, said that they would not prefer to not experience it because they believed that they had improved themselves. This approach, which Frankl describes as transforming a personal tragedy into a victory (Frankl, 2007), in a sense, gives the person the opportunity to gain from their losses. At the same time, Frankl states that logotherapy teaches people to say "yes to life regardless of anything" (Lukas, 1986). When one finds meaning to pain, pain becomes no longer suffering (Frankl, 2007). Pain is an undeniable human condition that needs to be faced in order to rise the life to a higher level (Wong, 2005).

Frankl developed the technique of the dereflection to prevent excessive intention and overthinking. The aim of this technique is to help the patients to overcome themselves and to act in accordance with creative and experimental values (Wong, 2002). In the study, the dereflection technique was used by asking the group members to determine their negative thoughts and alternative thoughts about the negative life event they experienced. The members of the group stated that it was more helpful to determine alternative positive thoughts in place of negative thoughts. Linden et al. (2007) stated that focusing on what people possess may also be effective in changing their focus of attention. Furthermore, Henrion (1987) reported that when the patients divert their focus of their thoughts from their mistakes to what they possess and their accomplishments, they will find new targets and make their lives valuable.

Individuals can refuse treatment because of the feeling of embitterment, they want the whole world to see how badly they were treated (Linden et al., 2007). In this study, during the pre-interview, individuals with high PTED symptom scores were found to refuse treatment. Some of the people who have been determined to exhibit PTED symptoms during the preliminary interview stated that they believed that nothing could be the solution to their problems. Based on the view that group work is an effective way to determine new attitudes (Welter, 2005), 10 sessions of logotherapy-oriented group counseling program prepared by the researcher were applied to the experimental group for 10 weeks. The application of psychological counseling program with logotherapyoriented group, there was a decrease observed in the PTED symptoms of individuals. In this context, the effects of psychological counseling with logotherapy-oriented individuals on PTED symptoms can be examined in the future studies. Testing the impact of different approaches on PTED can also help to come up with an idea of which approaches can help these individuals better.

To make a better distinction of PTED from PTSD and adjustment disorders, which possess similar characteristics, experimental studies can be conducted which compare individuals with symptoms related to these three disorders. About different traumatic experiences of individuals (dismissal, divorce, loss of a relative, finding out about a disease, etc.) the studies on PTED levels can be increased and the individuals working on mental health can obtain detailed information about the prognosticand treatment of the disorder. 


\section{References}

Altıntaş, E., \& Gültekin, M. (2005). Psychological counseling theories. (2nd ed.). İstanbul: Alfa Akademi Yayıncllı.

Budak, S. (2003). Dictionary of psychology. (2nd ed.). Ankara: Bilim ve Sanat Yayınları.

Büyüköztürk, Ş. (2012). Sosyal Bilimler için Veri Analizi El Kitabı: İstatistik, Araştırma Deseni Spss Uygulamaları ve Yorum. (17th ed.). Ankara: Pegem Yayıncılık.

Büyüköztürk, Ş., Çakmak, E. K., Akgün, Ö. E., Karadeniz, Ş., \& Demirel, F. (2008). Bilimsel Araştırma Yöntemleri. (2nd ed.). Ankara: Pegem Akademi.

Can, A. (2013). SPSS ile bilimsel araştırma sürecinde nicel veri analizi. (1 $1^{\text {st }}$ ed.). Ankara: Pegem Yayıncllık.

Frankl, V. (2005). The future of Franklian psychology. In G.E. Rice (Ed.), Franklian Psychology: An Introduction to Logotherapy (pp. 60-65). Texas: Viktor Frankl Institute of Logotherapy.

Frankl, V.E. (1973). The doctor and the soul. New York: Vintage Books.

Frankl, V. (1967a). The philosophical foundations of Logotherapy. Psychotherapy and existentialism. In J.C. Crumbaugh, H.O. Gerz, \& L.T. Maholick (Eds.), Selected papers on Logotherapy (pp. 1-18). New York, NY: Simon \& Schuster.

Frankl, V. (1967b). Dynamics and values. Psychotherapy and existentialism. In J.C. Crumbaugh, H.O. Gerz, \& L.T. Maholick (Eds.), Selected papers on Logotherapy (pp. 59-70). New York, NY: Simon $\&$ Schuster.

Frankl, V. (2007). Insanın anlam arayışı [Man's search for meaning]. ( $8^{\text {th }}$ ed.). S. Budak (Trans.). İstanbul: Öteki Psikoloji Dizisi.

Gölge, Z. B. (2005). Psychological problems occuring after sexual trauma. Archives of Neuropsychiatry, 42, 19-28.

Hasanoğlu, A. (2008). Suggestion of a new diagnostic category: posttraumatic embitterment disorder. Turkish Journal of Psychiatry, 19, 94-100.

Henrion, R. (1987). Making logotherapy a reality in treating alcoholics. The International Forum for Logotherapy, 10, 112-117.

Linden, M., Baumann, K., Lieberei, B., \& Rotter, M. (2007). Posttraumatic embitterment disorder, definition, evidence, diagnosis, treatment. USA: Hogrefe.

Linden, M., Rotter, M., Baumann, K., \& Lieberei, B. (2009). The post-traumatic embitterment disorder self-rating scale (PTED scale). Clinical Psychology \& Psychotherapy, 16, 139-147.

Linden M. (2003). Posttraumatic embitterment disorder. Psychotherapy and Psychosomatics, 72, 195-202.

Lukas, E.S. (1986). Meaning in suffering. California: Institute of Logotherapy Press.

Magwaza, A. S. (1997). Assumptive world of traumatized south african adults. The Journal of Social Psychology, 139(5), 622-630.

McAdams, D.P. (2012). Meaning and personality. In P.T.P. Wong (Ed.), The Human Quest for Meaning: Theories, Research and Applications (pp. 107-124). (2 $2^{\text {nd }}$ ed.). New York, NY: Taylor \& Francis Group.

Murray, J. A. (2001). Loss as a universal concept: a review of the literature to identify common aspects of loss in diverse situations. Journal of Loss and Trauma: International Perspectives on Stress \& Coping, 6, 219-241. 
Rice, G. E. (2004). Franklian psychology: meaning centered interventions. Texas: Viktor Frankl Institute of Logotherapy.

Taylor, S. E. (1983). Adjustment to threatening events: a theory of cognitive adaptation. American Psychologist, 38 (11), 1161-1173.

Ünal, S., Güney, S., Kartalcı, Ş., \& Rehyani, İ. (2011). The study of the realibility and validity of the Turkish version of post traumatic embitterment disorder self-rating scale (PTED self-rating scale). Düşünen Adam, The Journal of Psychiatry and Neurological Sciences, 24, 32-37.

Weinstein, N., Ryan, R. M., \& Deci, E. L. (2012). Motivation, meaning, and wellness: a selfdetermination perspective on the creation and internalization of personal meaning and life goals. In P.T.P Wong (Ed.).The human quest for meaning: theories, research and applications (pp. 81-106). (2 $2^{\text {nd }}$ ed.). New York, NY: Taylor \& Francis Group.

Welter, P. R. (2005). Franklian psychology: attitudinal change. Texas: Viktor Frankl Institute of Logotherapy Press.

Wong, P.T.P., Wong L.C.J., \& Scott, C. (2006). The positive psychology of transformation: beyond stress and coping. In Wong, P.T.P. \& Wong, L.C.J. (Eds.), Handbook of Multicultural perspectives on stress and coping (pp.1-60). New York, NY: Springer.

Wong P.T.P. (2005). Coping with the tsunami and its aftermath: A challenge to religious faith and the quest for meaning and hope. President's Column, 10, 1-8.

Wong P.T.P. (2002). Logotherapy, Encylopedia of Psychotherapy, 2, 107-113. 
In the writing process of the study titled "The Effect of Logotherapy Oriented Group Counseling on Post-Traumatic Embitterment Disorder", the rules of scientific, ethical and citation were followed; it was undertaken by the authors of this study that no falsification was made on the collected data. "Sakarya University Journal of Education Journal and Editor" had no responsibility for all ethical violations to be encountered, and all responsibility belongs to the authors and that the study was not submitted for evaluation to any other academic publishing environment. 